\title{
Effects of Butter and Cheese on Memory and Learning in Rats
}

\author{
Ali Heshmati ${ }^{1 *}$, Alireza Komaki ${ }^{2 *}$, Nafiseh Faraji ${ }^{2}$, Javad Karami ${ }^{1}$ \\ 1- Nutrition Health Research Center, Hamadan University of Medical Sciences, Hamadan, Iran \\ 2- Neurophysiology Research Center, Hamadan University of Medical Sciences, Hamadan, Iran
}

\section{A B S T R A C T}

Background and Objectives: Nutrition affects physical status, brain function, memory and learning. High-fat diets can cause memory impairment. The aim of this study was to investigate effects of cheese and butter on the memory and learning of male rats.

Materials and Methods: Totally, 24 Wistar male rats (8-week old) were divided into three equal groups and fed with high-fat chow diets (control group) or two experimental diets of butter and cheese for 12 weeks. Then, spatial memory and passive avoidance learning (PAL) were assessed using Morris water maze test and shuttle-box apparatus, respectively.

Results: In PAL test, step-through latencies in retention (STLr) test and time spent in the dark compartment (TDC) were significantly different between the groups. The step-through latencies in retention scores of the butter group were significantly lower than that of the control and cheese groups. However, dark compartment of the butter group was significantly greater than that of the control and cheese groups. In Morris water maze test, no significant differences were seen in escape latency, travelled distance and mean swimming speed of the various groups. During the probe trial, the butter groups spent significantly less time in the target quadrant than that the control and cheese groups did.

Conclusions: In general, cheese includes further favourable effects on spatial memory and PAL, compared to that butter groups do.

Keywords: Cheese, Butter, Spatial memory, Learning, Memory

\section{Introduction}

Learning and memory play fundamental roles in daily life of humans $(1,2)$. The basis of all training and learning depends on the process of memory. Identification of compounds that strengthen these two behavioural phenomena can help people who suffer from memory problems $(3,4)$. Studies have shown that diet can affect learning. Appropriate nutrition, in addition to its effects on physical function, includes tremendous effects on mental and brain functions in humans. Nutritional deficiencies may create psychological and mental illnesses (5-7). Consumption of saturated fat-rich foods and refined sugars is increasing in most countries. Excessive dietary intake of such foods can damage ability to learn and memorize $(8,9)$. These diets negatively affect memory and learning due to the generation of synapse plasticity defects and neurogenesis and hence harming cognitive functioning of the brain (10, 11). Studies have shown that inflammation and various cognitive and memory disorders are associated to excessive intake of refined sugars and saturated fats $(8,10-12)$. Inflammation is accompanied by increases in serum cytokines such as tumour necrosis factor alpha (TNFalpha) and interleukin 6 (IL-6) $(13,14)$. The hippocampus plays an important role in learning and memorizing and high-fat diets (HFD) decrease neurogenesis in the hippocampus (14, 15). A HFD increases plasma free fatty acids (FFA) and induces oxidative stress due to the accumulation of lipid peroxidation in the hippocampus (15). Previous studies have shown 
that obesity and consumption of HFD for nine weeks result in memory impairment while consumption of HFD for 18 weeks results in anxiety-like behaviours (16).

In the last two decades, several studies have been carried out on factors affecting memory. Effects of HFD on memory have been well documented $(8,10,11,17)$. However, effects of these diets depend on other factors. Cheese and butter contain high levels of fat; therefore, it seems that they affect the memory ability (18, 19). Iranians believe that cheese decreases the function of memory and brain cells and dampen people. However, there are other components such as folic acid and folate, vitamins $\mathrm{B}_{9}$ and $\mathrm{B}_{12}, \mathrm{~B}_{6}, \mathrm{D}, \mathrm{K}$ and $\mathrm{E}$, polyphenols, omega-3 fatty acids, iron, zinc, iodine, magnesium and selenium as well as antioxidants in these foods, which may positively affect memory through various mechanisms $(4,6,7,20)$. Moreover, these compounds may not affect memory as HFD may. The aim of this study was to investigate effects of cheese and butter on the memory and learning of rats.

\section{Materials and Methods}

\section{Animals and diets}

In this study, 24 Wistar male rats (eight8week old, weighing $262 \mathrm{~g} \pm 23$ ) were used. Rats were fed with a standard chow diet for three weeks. Then, animals were randomly divided into three groups of eight rats and fed with control or experimental diets for 12 weeks. Then, effects of a high-fat ad libitum diet (control) and two experimental diets were assessed. To prepare the experimental diets, butter $(25 \%)$ and cheese $(50 \%)$ were added to a milled high-fat ad libitum diet. These were shaped to roll pieces of $4-8 \mathrm{~cm}$, quite similar to commercial chow diets, and dried at room temperature. Fat contents of all diets (Table 1) were approximately similar to each other (nearly $24 \%$ ). At the end of the 12 weeks of nutritional intervention, behavioural studies were carried out. All procedures of research and animal care were approved by the Veterinary Ethics Committee, Hamadan University of Medical Sciences (VECHUMS), and carried out in accordance with the National Institutes of
Health Guide for Care and Use of Laboratory Animals.

\section{Behavioural studies}

\section{Passive avoidance learning (PAL) test}

Assessment of the passive avoidance memory was carried out using shuttle-box apparatus with a plexiglass box divided into two light and dark compartments (TDC and TLC, respectively) for use in training and testing. Dimensions of the device included $20 \times 20 \times 40 \mathrm{~cm}$. The TDC and TLC were separated using $8 \times 8 \mathrm{~cm}$ guillotine door. Metal bars were installed in the floor of both compartments, connecting to an electric circuit in TDC. A 100-watt lamp was installed $40 \mathrm{~cm}$ above TLC. All training and testing steps were carried out between 10:00 and 14:00. During training, each rat was hosted in TLC for $30 \mathrm{~s}$ for acclimatization. Then, the guillotine door opened, allowing the rat to go to TDC. After the rat entered TDC, the door closed and the animal was hosted for $30 \mathrm{~s}$. Then, the rat was referred to its cage. The rats that did not enter TDC within $120 \mathrm{~s}$ were excluded from the experiment. The entrance latency to TDC (stepthrough latency, STLa) was recorded. The habituation trial was repeated after $30 \mathrm{~min}$. The first acquisition trial was carried out $30 \mathrm{~min}$ later. In this step, the guillotine door was shut after the rat entered TDC and then the animal was foot shocked $(50 \mathrm{~Hz}, 0.8 \mathrm{~mA})$ for $2 \mathrm{~s}$. After $20 \mathrm{~s}$, the rat was removed from the apparatus and transferred to its cage for $2 \mathrm{~min}$. The acquisition trial was repeated and the acquisition of the passive avoidance response was considered successful if the rat did not enter TDC within 120 s. Numbers of electrical shocks and trials were documented (21-24). A retention test was carried out to assess long-term memory $24 \mathrm{~h}$ after training (21). Each rat was hosted in TLC, the guillotine door opened after $5 \mathrm{~s}$ and the step-through latency in the retention test (STLr) and the time spent in TDC were documented. Test terminated when the animal either entered TDC or stayed in TLC for $300 \mathrm{~s}$, indicating retention of the passive avoidance response. Electric shocks were not delivered while carrying out the retention test $(25,26)$. 


\section{Morris water maze test}

This test was used to assess spatial memory function of the animal (25). For assessment, a black cylindrical pool with a diameter of $180 \mathrm{~cm}$ and a height of $60 \mathrm{~cm}$ was filled with water $(22$ $\left.{ }^{\circ} \mathrm{C} \pm 1\right)$ to a depth of $25 \mathrm{~cm}$ and divided into four equal quadrants. A black circular escape platform (with a diameter of $15 \mathrm{~cm}$ ) was submerged in the middle of one of the quadrants at a depth of $2 \mathrm{~cm}$ below water. This quarter was considered as the target quarter. The pool was located inside a low-light room. As visual indications, signs with various geometric shapes were set on the four surrounding walls. To assess spatial memory, the animals were trained for four consecutive days with three trials per day as follows. The animal was soaked in water randomly from one of the four sides of the pool. The animal was allowed to swim and find the platform within $60 \mathrm{~s}$. The time between entry the water and finding the platform (escape latency) was recorded. If the animal was unable to find the platform within the specified time at any stages, the experimenter guided the animal to the platform. Rats spent $30 \mathrm{~s}$ on the platform and were then transferred to their cages for the next step. During four consecutive days of training, animals were subjected to three trials daily with submerged platform in the pool. All movements of the animals were recorded using video camera (Nikon, Melville, NY, USA) connected to a computer. On Day 5, each rat did a 60-s probe trial and a visible platform trial. No platforms were present during the probe trial. The escape latency (the time until reaching the target platform), travel distance, average swimming speed and average time spent in target quarter as an indicator of the spatial memory function of the animal were recorded $(22,27)$.

\section{Measurement of dietary compounds}

Contents of moisture, protein, carbohydrate and fat of each diet were analysed using ovendrying, Kjeldahl, phenol-sulphuric acid and Soxhlet methods, respectively (28).

\section{Fatty acid analysis}

After extraction of fats, methyl ester of the fatty acids (FA) was prepared and analysed according to previous studies (29). Varian CP3800 Gas Chromatography System (Varian Inc., CA, USA) equipped with a flame ionization detector and CP-Sil 88 Columns (length, internal diameter and thickness of $100 \mathrm{~m}, 0.25 \mathrm{~mm}$ and $0.25 \mu \mathrm{m}$, respectively) were used for the analysis of FAs. Nitrogen was used as carrier (at $68 \mathrm{PSI})$ and makeup (25 $\left.\mathrm{mL} \mathrm{min}^{-1}\right)$ gases. Air

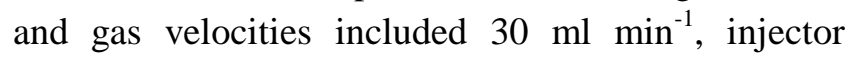
and detector temperatures included $260{ }^{\circ} \mathrm{C}$ and the injection volume included $1 \mu 1$. The oven temperature was set at $140{ }^{\circ} \mathrm{C}$ for $5 \mathrm{~min}$ and then increased to $240{ }^{\circ} \mathrm{C}$ at a rate of $4{ }^{\circ} \mathrm{C} \mathrm{min}^{-1}$ and held for $15 \mathrm{~min}$. The analysis time for FAs included $70 \mathrm{~min}$.

\section{Statistical analysis}

Data analysis was carried out using SPSS Software v.20.0. The mean and standard deviation (SD) of the data were reported. Oneway ANOVA was used to show differences between the groups. Comparison of means of the experimental groups with control group was carried out using Tukey's test. A $P<0.05$ value was considered as significant level.

\section{Results}

\section{Compositions of various diets}

Compositions of various diets are shown in Table 1. Quantities of fats in control, butter and cheese groups included 24.17, 24.08 and $24.07 \%$, respectively. In cheese group, quantity of protein $(18.28 \%)$ was higher than that of two other groups while it included the lowest quantity of carbohydrate (28.43\%).

\section{Quantities of saturated and unsaturated fatty acids}

Quantities of saturated and unsaturated fatty acids (SFA and UFA, respectively) in diets are shown in Table 2. The highest quantities of SFA (55.62\%) and polyunsaturated fatty acids (PUFA) $(49.47 \%$ ) were detected in butter diets and in control groups, respectively. 
Ali Heshmati, et al: The influence of butter and cheese on memory on memory

Table 1. Compositions of diets in control and experimental groups (\% w/w)

\begin{tabular}{|c|c|c|c|c|}
\hline Diet type & Moisture & Protein & Carbohydrate & Fat \\
\hline Control (high-fat chew diet) & $13.70 \pm 2.16$ & $14.67 \pm 1.65$ & $39.41 \pm 1.65$ & $24.17 \pm 1.41$ \\
\hline Butter diet & $13.70 \pm 0.95^{\#}$ & $14.38 \pm 0.65^{\#}$ & $39.67 \pm 0.98^{\#}$ & $24.08 \pm 1.21$ \\
\hline Cheese diet & $27.33 \pm 1.01^{*}$ & $18.28 \pm 0.74^{*}$ & $28.43 \pm 1.31^{*}$ & $24.07 \pm 0.75$ \\
\hline
\end{tabular}

Table 2. Fatty acid compositions of diets in control and experimental groups

\begin{tabular}{lcccc}
\hline Fatty acid & Control & Butter & Cheese & $P$ value \\
\hline$\sum$ SFA & $16.08 \pm 0.19$ & $55.62 \pm 1.36^{* \#}$ & $40.63 \pm 1.16^{*}$ & $<0.001$ \\
$\sum$ MUFA & $26.01 \pm 1.03$ & $29.43 \pm 0.67^{* \#}$ & $37.96 \pm 1.09^{*}$ & $<0.001$ \\
$\sum$ PUFA & $49.47 \pm 1.78$ & $7.87 \pm 0.18^{* \#}$ & $16.77 \pm 0.48^{*}$ & $<0.001$ \\
$\sum$ n-9 UFA & $25.09 \pm 0.94$ & $26.47 \pm 0.61^{* \#}$ & $33.02 \pm 0.95^{*}$ & $<0.001$ \\
$\sum$ n-6 PUFA & $42.7 \pm 0.18$ & $7.56 \pm 0.17^{* \#}$ & $14.81 \pm 0.42^{*}$ & $<0.001$ \\
$\sum$ n-3 PUFA & $4.38 \pm 0.01$ & $0.31 \pm 0.01^{* \#}$ & $1.95 \pm 0.06^{*}$ & $<0.001$ \\
$\sum$ trans & $0.58 \pm 0.08$ & $2.96 \pm 0.07^{* \#}$ & $4.94 \pm 0.14^{*}$ & $<0.001$ \\
$\sum$ n-6 PUFA/ $\sum$ n-3 PUFA & $9.72 \pm 0.21$ & $25.16 \pm 0.5^{* \#}$ & $7.73 \pm 0.15^{*}$ & $<0.001$ \\
\hline
\end{tabular}

* and \# indicated statistically significant differences $(P<0.05)$, compared to control and cheese groups, respectively. One-way ANOVA and Duncan's test were used to show differences within the groups. SFA, total saturated fatty acid; total MUFA, total monounsaturated fatty acid; total PUFA, total polyunsaturated fatty acids; P/S, the ratio of polyunsaturated fatty acids to saturated fatty acids

\section{Passive avoidance learning}

Results of statistical analysis showed no significant differences in the numbers of trials (Fig. 1A) conducted to achieve learning in passive avoidance test in control, butter and cheese groups $(1.53,1.44$ and 1.21 , respectively). Step-through latencies in acquisition (STLa) test did not differ within the various groups (Fig. 1B). The retention test, which was carried out $24 \mathrm{~h}$ after training, showed a significant difference in step-through latencies in acquisition (STLr) test within the groups $(P<0.05)$. The STLr of the butter group $(220.44 \mathrm{~s} \pm 6.32)$ was significantly lower than that of control $(278.96 \mathrm{~s} \pm 10.01)$ and cheese (248.6s \pm 10.51$)$ groups. A statistically significant difference was seen in the variable of time spent in TDC within the experimental groups. Results showed that TDC of the butter group $(152.04 \mathrm{~s} \pm 7.21)$ was significantly greater than that of control $(85.01 \mathrm{~s} \pm 5.92)$ and cheese (135.2s \pm 6.24$)$ groups $(P<0.05)$.

\section{Morris water maze}

In Morris water maze test (Fig. 2A), findings showed no significant differences within escape latency of the various groups (data of Day 4 included control group, 34.15s \pm 3.42 ; butter group, $37.14 \mathrm{~s} \pm 2.72$; and cheese group, $30.9 \mathrm{~s} \pm 2.09$ ). Therefore, it can be concluded that the rats in all groups were able to learn the labour. Moreover, statistical analysis showed no significant differences in travelled distance (Fig. 2B) in Morris water maze test in all groups (data of Day 4 included control group, 701.25 \pm 43.20 $\mathrm{cm}$; butter group, $914.12 \pm 33.71 \mathrm{~cm}$; and cheese group, $650.55 \pm 29.76 \mathrm{~cm}$ ) and mean swimming speed (control group, $2.82 \pm 0.12 \mathrm{~s}$; butter group, $2.95 \pm 0.09 \mathrm{~s} ;$ and cheese group, $3.09 \pm 0.08 \mathrm{~s}$ ). During the probe trial, time spent in the target quadrant (Fig. 2) showed significant differences within various groups. The butter group $(18.18 \mathrm{~s} \pm 1.75)$ spent a significantly lower time in the target quadrant than that cheese $(23.13 \mathrm{~s} \pm 1.52)$ and control $(23.65 \mathrm{~s} \pm 1.25)$ groups did. 
A
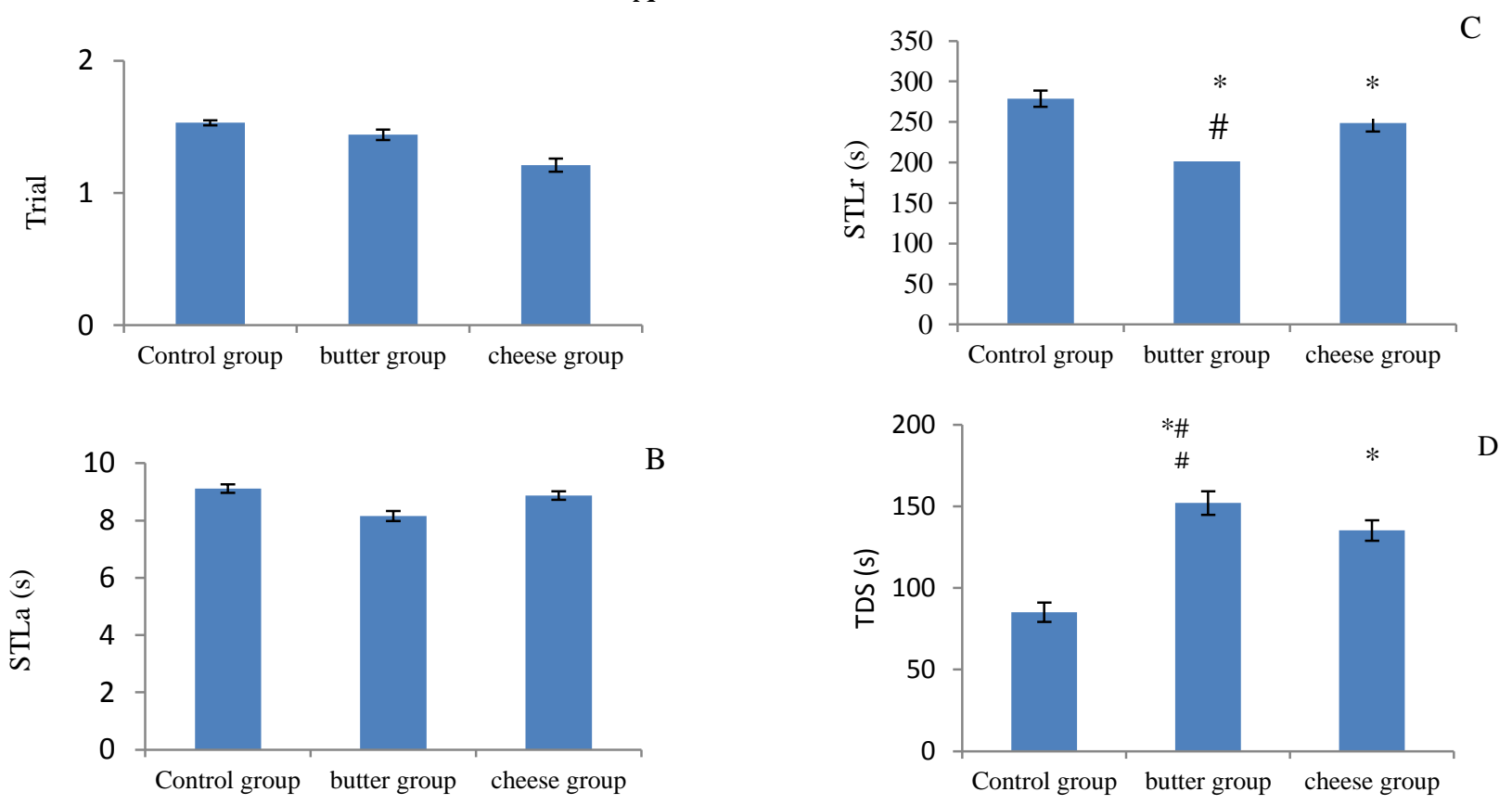

Figure 1. Numbers of trials to achieve learning in passive avoidance test (A), step-through latency in acquisition trial (STLa) (B), step-through latency in retention trial (STLr) (C), and time spent in the dark compartment (TDC) of the passive avoidance learning test (D). Each column and bar represents mean $\pm \mathrm{SD}$ (standard deviation). $*$ and \# indicated statistically significant differences $(P<0.05)$, compared to control and cheese groups, respectively
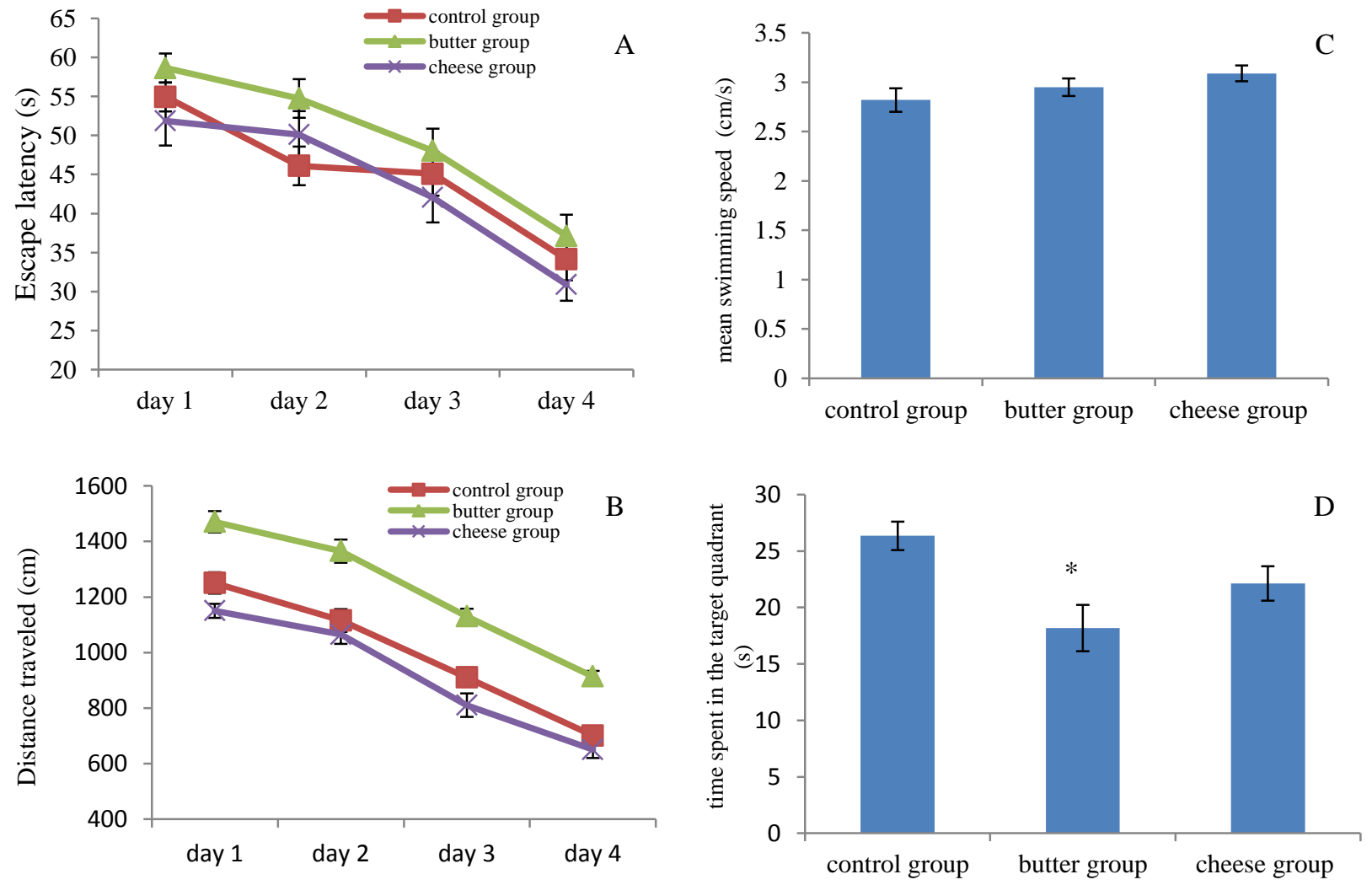

Figure 2. A) Escape latency; B) distance traveled; C) mean swimming speed; and D) time spent in the target quadrant in Morris water maze test. Each column or point and bar represents mean $\pm \mathrm{SD}$ (standard deviation). *Statistically significant differences, compared to control group $(P<0.05)$ 


\section{Discussion}

Learning ability and memory are human vital characteristics and scientific advancements. Dairy products are important groups in food pyramid and effectively contribute to provide human nutritional requirements $(18,30)$. Cheese is a highly nutritious dairy product including many varieties. For example, Iranian white cheese included the highest production and consumption rates within various cheeses available in Iran. During cheese ripening, some proteins break down and convert into peptides with antioxidant properties

Epidemiological studies have shown that diets with antioxidant compounds can improve memory performance $(20,32)$. It is believed that cheese affects human memory. However, a little research have been carried out on this issue. The present study was carried out to investigate effects of butter and cheese on spatial and avoidance memory of rats. The shuttle-box apparatus and Morris water maze were used to assess spatial and avoidance memory. Previous studies have shown that SFA and cholesterol damage cognitive memory and hippocampus morphology in rats (33). In the current study, fat contents of various diets acted similarly (approximately 24\%); however, types of the FA varied between various diets. Diets containing butter included the highest levels of SFA $(55.62 \%)$, followed by cheese diets $(40.63 \%)$. Results of the assessment of learning and memory tests in the present study indicated inverse relationships of the learning and memory with the quantities of dietary SFA. In addition to effects of FA on memory, free radicals have been shown to be generated during metabolism and mitochondrial respiration resulting in oxidative stress and causing abnormal brain function in aging. Oxidative stress during aging causes oxidation of lipids and proteins in central nervous system (CNS); thus, damaging the brain cells (34). Quantities of the free radicals produced in various regions of the brain such as hippocampus, which includes a greater oxygen consumption, are higher in older rats than younger rats (35). Zare et al. (2011) found that oils such as sesame oil with higher
UFA included better effects on passive avoidance, compared to that SFA and cholesterol-rich oils such as butter oil did. A possible reason is attributed to effects of the highlighted compounds on the oxidative stress control, changes in UFA of the neuron membranes and changes in cholesterol synthesis pathways (36).

Several nutritional factors play important roles in memory processing. Of the most important nutritional factors are antioxidant compounds such as flavonoids (37). Moreover, nutrients such as iodine, iron, zinc, folate, vitamins $B_{1}$ and $B_{12}$, selenium, and essential fatty acids (EFA) affect learning. Iodine is needed for the formation of thyroxin, which is an essential nutrient for the brain. Iron is necessary for oxygenation and energy production in nervous cells. Zinc plays an important role in cognitive development. Presence of vitamin $B_{1}$ is necessary for energy production and utilization of glucose by nervous tissues. Vitamin $B_{12}$ is directly involved in synthesis of neurotransmitters. Selenium contributes to the protection of nervous tissues against aggression by free radicals (7). In general, quantities of minerals are higher in cheese than butter (38). Therefore, another possible reason for the higher memory and learning abilities of the rat groups received cheese it linked to high mineral levels of cheese. In addition, cheese contains several bioactive peptides that may affect body functions, including learning and memory (6).

\section{Conclusion}

In this study, effects of butter and cheese on memory and learning of male rats were assessed. In summary, results have shown that cheese includes more favourable effects on spatial memory and avoidance learning of rats, compared to that butter does. However, further comprehensive studies on long-term effects of diets seem necessary. It is suggested to assess effects of these foods on various parts of the CNS. Since the current study was carried out on rats, it is necessary to investigate effects of these diets on humans to achieve further realistic results. 


\section{Acknowledgement}

The authors thank staff in Neurophysiology Research Center for helping this study.

\section{Financial disclosure}

The authors declare no financial interest.

\section{Funding/Support}

This study was funded by a grant (Grant No. 950304951) from Hamadan University of Medical Sciences, Hamadan, Iran.

\section{References}

1. Lieberman DA. Human learning and memory: Cambridge University Press; 2011.

2. Horton DL, Mills CB. Human learning and memory. Annu Rev Psychol. 1984;35(1):361-94.

3. Asadbegi M, Yaghmaei P, Salehi I, Komaki A, Ebrahim-Habibi A. Investigation of thymol effect on learning and memory impairment induced by intrahippocampal injection of amyloid beta peptide in high fat diet- fed rats. Met Brain Dis. 2017;32(3):827-39.

4. Poulose SM, Miller MG, Scott T, Shukitt-Hale B. Nutritional factors affecting adult neurogenesis and cognitive function. Adv Nutr. 2017;8(6):80411.

5. Rao TS, Asha M, Ramesh B, Rao KJ. Understanding nutrition, depression and mental illnesses. Indian J Psychiat. 2008;50(2):77.

6. Bourre JM. Effects of nutrients (in food) on the structure and function of the nervous system: update on dietary requirements for brain. Part 2 : macronutrients. J Nutr Health Aging. 2006;10(5):386-99.

7. Bourre JM. Effects of nutrients (in food) on the structure and function of the nervous system: update on dietary requirements for brain. Part 1: micronutrients. J Nutr Health Aging. 2006;10(5):377-85.

8. Molteni R, Barnard R, Ying Z, Roberts C, GomezPinilla F. A high-fat, refined sugar diet reduces hippocampal brain-derived neurotrophic factor, neuronal plasticity, and learning. Neurosci. 2002;112(4):803-14.

9. Francis H, Stevenson R. The longer-term impacts of Western diet on human cognition and the brain. Appetite. 2013;63:119-28.

10. Cordner ZA, Tamashiro KL. Effects of high-fat diet exposure on learning \& memory. Physiol Behav. 2015;152:363-71.

11. Cui Y, Shu Y, Zhu Y, Shi Y, Le G. High-fat diets impair spatial learning of mice in the Y-maze paradigm: ameliorative potential of $\alpha$-lipoic acid. J. Med. Food. 2012;15(8):713-7.
12. Kelly TJ, Serruya M. Integrative Approaches to Cognitive Decline. Integr Psychiat Brain Health. 2018:431.

13. Illán-Gómez F, Gonzálvez-Ortega $\mathrm{M}$, Orea-Soler I, Alcaraz-Tafalla MS, Aragón-Alonso A, Pascual-Díaz $M$, et al. Obesity and inflammation: change in adiponectin, C-reactive protein, tumour necrosis factor-alpha and interleukin-6 after bariatric surgery. Obes Surg. 2012;22(6):950-5.

14. Jankowsky JL, Patterson PH. Cytokine and growth factor involvement in long-term potentiation. Mol Cell Neurosci. 1999;14(4):27386.

15. van Praag H, Schinder AF, Christie BR, Toni N, Palmer TD, Gage FH. Functional neurogenesis in the adult hippocampus. Nature. 2002;415(6875):1030-4.

16. Yamato M, Shiba T, Yoshida M, Ide T, Seri N, Kudou W, et al. Fatty acids increase the circulating levels of oxidative stress factors in mice with diet- induced obesity via redox changes of albumin. FEBS J. 2007;274(15):3855-63.

17. Freeman LR, Haley-Zitlin V, Rosenberger DS, Granholm A-C. Damaging effects of a high-fat diet to the brain and cognition: a review of proposed mechanisms. Nutr Neurosci. 2014;17(6):241-51.

18. Crichton GE, Elias MF, Dore GA, Robbins MA. Relation between dairy food intake and cognitive function: The Maine-Syracuse Longitudinal Study. Int Dairy J. 2012;22(1):15-23.

19. Crichton GE, Murphy KJ, Howe PR, Buckley JD, Bryan J. Dairy consumption and working memory performance in overweight and obese adults. Appetite. 2012;59(1):34-40.

20. Perrig WJ, Perrig P, Stähelin HB. The relation between antioxidants and memory performance in the old and very old. J Am Geriatr Soc. 1997;45(6):718-24.

21. Khodamoradi N, Komaki A, Salehi I, Shahidi S, Sarihi A. Effect of vitamin E on lead exposureinduced learning and memory impairment in rats. Physiol Behav. 2015;144:90-4.

22. Moradkhani S, Salehi I, Abdolmaleki S, Komaki A. Effect of Calendula officinalis hydroalcoholic extract on passive avoidance learning and memory in streptozotocin-induced diabetic rats. Anc Sci Life. 2015;34(3):156-61.

23. Shiri M, Komaki A, Oryan S, Taheri M, Komaki $\mathrm{H}$, Etaee F. Effects of cannabinoid and vanilloid receptor agonists and their interaction on learning and memory in rats. Can J physiol Pharmacol. 2017;95(4):382-7.

24. Zarrinkalam E, Heidarianpour A, Salehi I, Ranjbar K, Komaki A. Effects of endurance, 
resistance, and concurrent exercise on learning and memory after morphine withdrawal in rats. Life Sci. 2016;157:19-24.

25. Rezvani-Kamran A, Salehi I, Shahidi S, Zarei M, Moradkhani S, Komaki A. Effects of the hydroalcoholic extract of Rosa damascena on learning and memory in male rats consuming a high-fat diet. Pharm Biol. 2017;55(1):2065-73.

26. Ganji A, Salehi I, Nazari M, Taheri M, Komaki A. Effects of Hypericum scabrum extract on learning and memory and oxidant/antioxidant status in rats fed a long-term high-fat diet. Metab Brain Dis. 2017;32(4):1255-65.

27. Zarrinkalam E, Ranjbar K, Salehi I, Kheiripour N, Komaki A. Resistance training and hawthorn extract ameliorate cognitive deficits in streptozotocin-induced diabetic rats. Biomed Pharmacother. 2018;97:503-10.

28. Horwitz W. Official methods of analysis of the AOAC: Association of Official Analytical Chemists; 2000.

29. Heshmati A. Effects of margarine and butter on lipid profile and serum fatty acid composition in rats. Koomesh. 2016;18(1):180-8.

30. Pereira PC, Vicente F. Milk Nutritive Role and Potential Benefits in Human Health. Nutrients in Dairy and their Implications on Health and Disease: Elsevier; 2018. p. 161-76.

31. Revilla I, González-Martín M, Vivar-Quintana A, Blanco-López M, Lobos-Ortega I, HernándezHierro J. Antioxidant capacity of different cheeses: Affecting factors and prediction by near infrared spectroscopy. J Dairy Sci. 2016;99(7):5074-82.
32. Zandi PP, Anthony JC, Khachaturian AS, Stone SV, Gustafson D, Tschanz JT, Norton MC, Welsh-Bohmer KA, Breitner JC. Reduced risk of Alzheimer disease in users of antioxidant vitamin supplements: the Cache County Study. Arch Neurol. 2004;61(1):82-8.

33. Granholm A-C, Bimonte-Nelson HA, Moore AB, Nelson ME, Freeman LR, Sambamurti K. Effects of a saturated fat and high cholesterol diet on memory and hippocampal morphology in the middle-aged rat. J Alzheimer's Dis. 2008;14(2):133-45.

34. Floyd RA, Hensley K. Oxidative stress in brain aging: implications for therapeutics of neurodegenerative diseases. Neurobiol Aging. 2002;23(5):795-807.

35. Emami M, Hosseini A, Saeedi A, Golbidi D, Reisi P, Alaei H. Effect of red grape juice on learning and passive avoidance memory in rats. $\mathrm{J}$ Isfahan Med School. 2010;104(28):1-7.

36. Zare K, Tabatabaei SRF, Shahriari A, Jafari Ra. Effect of Butter and Sesame Oils on Avoidance Memory of Diabetic Rat. Iran J Diabetes Obes. 2011;3(2):65-71.

37. Spencer JP. Food for thought: the role of dietary flavonoids in enhancing human memory, learning and neuro-cognitive performance: Symposium on 'Diet and mental health'. $P$ the Nutr Soc. 2008;67(2):238-52.

38. Lante A, Lomolino G, Cagnin M, Spettoli P. Content and characterisation of minerals in milk and in Crescenza and Squacquerone Italian fresh cheeses by ICP-OES. Food Control. 2006;17(3):229-33. 